\title{
Physician adherence to societal guidelines following colonoscopy with polypectomy
}

\author{
Jonathan Naftalic, Timna Naftalib,d, Elizabeth Halfa,c, Itai Maza, , Assaf Steinn, ${ }^{\mathrm{b}, \mathrm{d}}$, Matti Waterman ${ }^{\mathrm{a}, \mathrm{c}}$, \\ Ilia Sergeyev ${ }^{b, d}$, Kamal Yassin ${ }^{a, c}$, Irit Chermesh ${ }^{a, c}$, Iyad Khamaysia,c, Fabiana Sklerovsky-Benjamfinov ${ }^{b, d}$, \\ Yaacob Vayner, ${ }^{b, d}$, Afif Yaccobb ${ }^{a, c}$, Rita Brun ${ }^{a, c}$, Tarek Saadia,c, Amir Klein ${ }^{a, c}$
}

Rambam Health Care Campus, Haifa; Meir Medical Centre; Technion-Israel Institute of Technology, Haifa; Tel Aviv University, Sackler School of Medicine, Tel Aviv, Israel

\section{Abstract}

a Department of Gastroenterology, Rambam Health Care Campus, Haifa (Jonathan Elizabeth Half, Itai Maza, Matti Waterman, Kamal Yassin, Irit Chermesh, Iyad Khamaysi, Afif Yaccob, Rita Brun, Tarek Saadi, Amir Klein); ${ }^{b}$ Department of Gastroenterology, Meir Medical Centre (Timna Naftali, Assaf Stein, Ilia Sergeyev, Fabiana Sklerovsky-Benjamfinov, Yaacob Vayner); 'Technion-Israel Institute of Technology, Haifa (Jonathan Naftali, Elizabeth Half, Itai Maza, Matti Waterman, Kamal Yassin, Irit Chermesh, Iyad Khamaysi, Afif Yaccob, Rita Brun, Tarek Saadi, Amir Klein); ${ }^{\text {TTel Aviv }}$ University, Sackler School of Medicine, Tel Aviv (Timna Naftali, Assaf Stein, Ilia Sergeyev, Fabiana Sklerovsky-Benjamfinov, Yaacob Vayner), Israel

\section{Conflict of Interest: None}

Correspondence to: Dr Amir Klein, Rambam Health Care Campus and the Faculty of Medicine, Technion Institute of Technology, Haifa Israel, e-mail: aaklein4@gmail.com

Received 5 April 2020; accepted 25 June 2020; published online 8 July 2020

DOI: https://doi.org/10.20524/aog.2020.0523

\section{Introduction}

Colorectal cancer (CRC) is a leading cause of cancer-related morbidity and mortality worldwide [1]. Most colon cancers develop from benign adenomatous/serrated polyps; however, less than $5 \%$ of the polyps become cancer [2]. Transformation of a polyp into an adenocarcinoma is a gradual process that occurs over 5-10 years and involves acquired genetic, epigenetic and molecular changes [3]. This gradual process creates the opportunity for intervention and prevention.

Most CRCs are sporadic and risk factors include family history, age, environmental risk factors, excessive alcohol consumption, smoking, and certain foods [4]. A very important risk factor for CRC is the presence of polyps (especially advanced polyps) during the index colonoscopy [3]. Studies have shown that colonoscopy with polypectomy reduces the 
relative risk of CRC by $53 \%$ [5], reduces the incidence of CRC by $48 \%$, and reduces mortality from CRC by $65 \%[6,7]$.

Guidelines of gastroenterological societies recommend surveillance following polypectomy, according to the patient's risk of developing additional polyps. The degree of risk is determined by the polyp size, its histological characteristics and the level of dysplasia. These risk factors form the basis for surveillance recommendations (Supplementary Table 1). Too stringent recommendations (shorter intervals between colonoscopies) will impose a significant burden on the patient and the healthcare system, while recommendations that are too lenient (long intervals between colonoscopies) can lead to missed pre-cancerous polyps and the development of cancer $[8,9]$.

\section{Materials and methods}

\section{Study design and participants}

This was a prospective observational and interventional study conducted at 2 academic centers in Israel. The study population were consultant gastroenterologists who perform elective colonoscopies with polypectomy. The study protocol conformed to the ethical guidelines of the 1975 Declaration of Helsinki, as reflected in a priori approval by the institution's human research committee.

In the first phase of the study, we examined current practices. Reports of colonoscopies with polypectomies were prospectively collected over a period of 3 months, and the endoscopist's recommendations after the colonoscopy were reviewed and compared with the guidelines. We included patients undergoing colonoscopy with polypectomy and excluded patients with a history of CRC, patients with inflammatory bowel disease, and patients with familial adenomatous polyposis, Lynch syndrome, $\mathrm{MYH}$-associated polyposis, or juvenile polyposis.

After completing the first phase of the study, we conducted an intervention that included several components. First, each physician received a personal report regarding his postpolypectomy recommendations and their concordance with societal guidelines. Second, we presented (in an anonymous form) the results from the first phase in a departmental meeting and reaffirmed current guidelines, including a reference chart to help with decision making (Fig. 1). We then initiated a discussion of the steps that could be taken in order to increase the overall number of recommendations and improve adherence to guidelines. We updated the electronic form (Fig. 2) and, finally, we sent an e-mail with an explanation of the new system and the guidelines reference chart to all participating physicians (Fig. 1).

In the second phase, following the intervention, we again prospectively collected data over a period of 3 months. The exact time frame for data collection for both phases of the study was not disclosed to the physicians.

\section{Patient data collection}

For every patient, we collected the following data: demographic data (age, sex), endoscopic report (indications, morphology, size, location and number of polyps, quality of bowel preparation according to the Boston bowel preparation scale [10]), pathologic report (size and type of polyp, dysplasia, margins) and the physician's recommendation.

\section{Statistical analysis}

Descriptive data are presented as percentages and numbers. Categorical variables were describe using frequency and percentage. Pearson's chi-square test was used to compare categorical variables. A P-value $<0.05$ was considered significant. All statistical analyses were performed using IBM SPSS Statistics for Windows, Version 23.0 (IBM Corp., Armonk, NY.

Table 1 Baseline characteristics of the study population. There was no significant difference between populations (before and after intervention)

\begin{tabular}{lcc}
\hline Variable & Before intervention $(\mathrm{n}=349)$ & After intervention $(\mathrm{n}=297)$ \\
\hline Age & $65.83 \pm 10.14$ & $65.48 \pm 10.14$ \\
Sex & & 190 \\
Male & 231 & 106 \\
Female & 118 & 0.63 \\
Colonoscopy indication & & 17 \\
Medical referral for polypectomy & 23 & 68 \\
Known previous polyps & 98 & 11 \\
Stomach ache & 16 & 6 \\
Imaging finding & 10 & 103 \\
GI bleeding, anemia, positive occult blood test & 94 & 20 \\
Changes in bowel movements (constipation, diarrhea) & 30 & 26 \\
Family history of CRC & 27 & 49 \\
Screening for CRC & 57 & 4 \\
Unexplained weight lost & 12 & 37 \\
Other & 12 & 0.35 \\
\hline
\end{tabular}

\footnotetext{
*Some patients had more than one indication
}

GI, gastrointestinal; CRC, colorectal cancer 


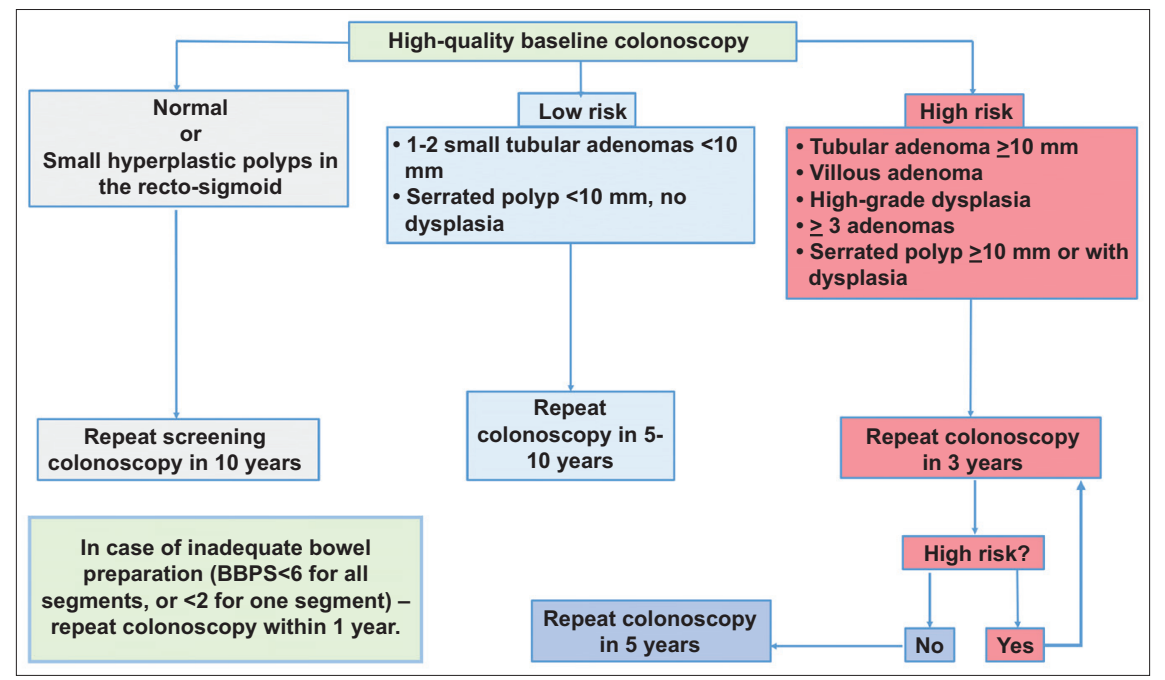

Figure 1 The chart created for the new reporting platform and introduced in the intervention phase, in order to facilitate more accurate recommendations

BBPS, Boston bowel preparation score

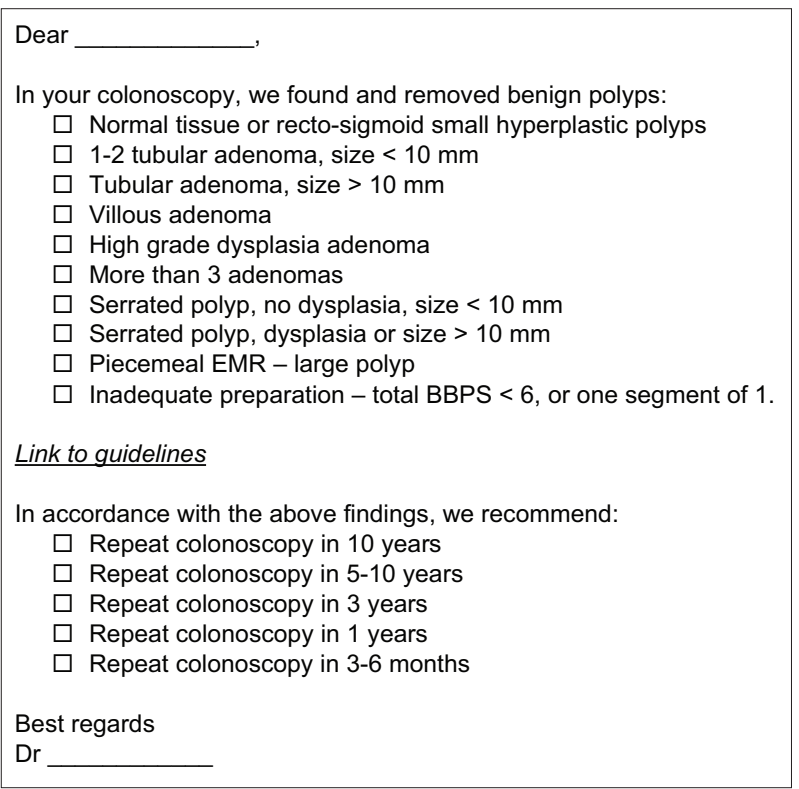

Figure 2 Example of the dedicated page for post-polypectomy recommendations in the medical file. The physician can select the appropriate recommendation for each polyp type and can also view a page with the guidelines (Fig. 1). The computer then automatically generates a letter, mailed to the patient along with the pathology report BBPS, Boston bowel preparation score; EMR, endoscopic mucosal resection

\section{Results}

A total of 646 patients who underwent colonoscopy with polypectomy were included in the study, 349 cases in the first phase and 297 in the second phase. In this population, 65\% were male and the average age was $65.67 \pm 10.01$ years. Table 1 shows the baseline demographic and clinical characteristics of our cohort.

In the first phase of the study, 266/349 patients (76\%) received a clearly documented written recommendation for surveillance colonoscopy. A recommendation consistent with societal guidelines was given in 174/266 (65\%) patients. Compared with the guidelines, the recommended timing of surveillance was too early in 66 patients $(25 \%)$ and too late in 26 patients (10\%) (Table 2 ).

In the second phase of the study, 254/297 patients (86\%) received a recommendation for surveillance colonoscopy. A recommendation consistent with societal guidelines was given in 199/254 (78\%) patients. Compared with the guidelines, the recommended timing of surveillance was too early in 48 patients (19\%) and too late in 7 patients (3\%) (Table 2).

The patients who did not receive any documented recommendation in the first and second phases might not have received any recommendation, or they might have received a recommendation not documented. Some recommendations were given by telephone or in handwriting on the pathological report sent to the patient. These data were unfortunately not available.

After the intervention, patients received significantly more recommendations ( $86 \%$ vs. $76 \%, \mathrm{P}=0.003$ ), and these were much more consistent with societal guidelines ( $78 \%$ vs. $65 \%$, $\mathrm{P}=0.001$ ), (Table 2, Fig. 3).

We compared different variables between adherent and non-adherent groups (Supplementary Table 2). We found that bowel preparation $(\mathrm{P}=0.001)$, pathologic size of polyp $(\mathrm{P}=0.001)$, dysplasia $(\mathrm{P}=0.003)$, and high-risk polyps $(\mathrm{P}=0.01)$ had a statistically significant influence on adherence, both before and after intervention.

\section{Discussion}

Recommendation for surveillance colonoscopy should balance the need for preventing CRC, while maintaining adequate use of medical resources and minimizing patient discomfort and morbidity. Previous data on compliance with 
Table 2 Physicians' recommendations to guidelines between before and after intervention. Dark grey represents too early recommendations, light gray represent too late recommendations, and medium gray represents consistent recommendations

\begin{tabular}{|c|c|c|c|c|c|c|}
\hline \multicolumn{7}{|c|}{ Prior to intervention } \\
\hline & & \multicolumn{5}{|c|}{ Time recommendation - Physicians } \\
\hline & & within 1 year & 2 years & 3 years & 5 years & 10 years \\
\hline \multirow{4}{*}{ Time recommendation - Guidelines } & 1 year & 59 & 1 & 9 & 2 & 0 \\
\hline & 3 years & 41 & 2 & 49 & 14 & 0 \\
\hline & 5 years & 6 & 0 & 17 & 66 & 0 \\
\hline & 10 years & 0 & 0 & 0 & 0 & 0 \\
\hline
\end{tabular}

\begin{tabular}{cccccccc}
\hline & \multicolumn{5}{c}{ Time recommendation - Physicians } \\
\cline { 3 - 8 } & & within 1 year & 2 years & 3 years & 4 years & 5 years & 10 years \\
\hline \multirow{2}{*}{ Time recommendation - Guidelines } & 1 year & 50 & 1 & 0 & 0 & 1 & 0 \\
& 3 years & 26 & 2 & 66 & 0 & 5 & 0 \\
& 5 years & 4 & 0 & 14 & 2 & 0 & 0 \\
& 10 years & 0 & 0 & 0 & 0 & 3 \\
\hline
\end{tabular}

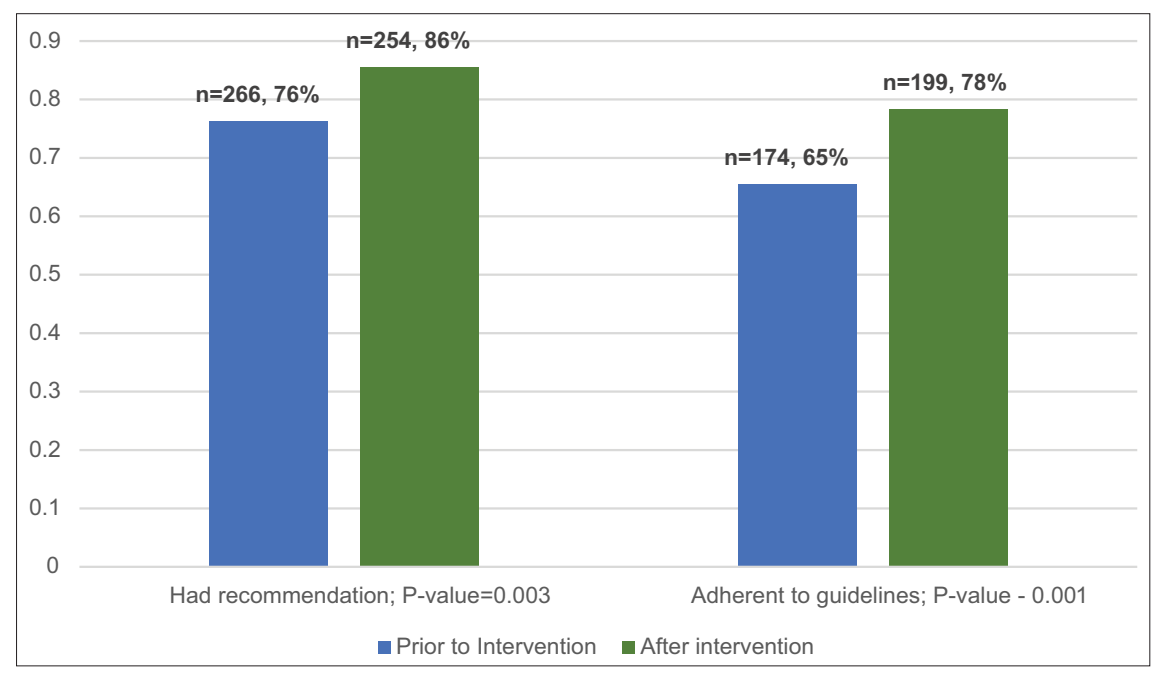

Figure 3 Comparison between recommendations and adherence to guidelines prior and after intervention

guidelines are conflicting and, to the best of our knowledge, none of the previous studies examined the effect of intervention on adherence to guidelines.

In a large observational study, including 25 centers in the United States, $36 \%$ of physicians were non-compliant with guidelines, with a variation of $3-80 \%$ between institutions. This study also showed that, in $94.6 \%$ of the cases, physicians recommended surveillance colonoscopy earlier than required according to the guidelines. In that study, recommendations were mainly influenced by the histologic nature of the resected polyp and by the quality of bowel preparation [11]. In another study, more than $50 \%$ of physicians recommended repeat colonoscopy after 3 years or less for small adenomas, which according to the guidelines should have been after 5 years. In that study, unnecessary short intervals for repeat colonoscopy were also recommended for hyperplastic polyps in $24 \%$ of cases [12]. On the other hand, Menees SB et al evaluated physician compliance with guideline recommendations in average-risk patients undergoing colonoscopy with polypectomy of 1-2 small polyps. They found that more than $90 \%$ of the recommendations were consistent with the guidelines, and that this was again significantly influenced by the quality of bowel preparation [13]. These studies had several limitations, including their retrospective design, reliance on physicians' reports, which can promote recall bias, and the small number of cases. 
We performed a 2-phase prospective study, which also included an intervention session in 2 academic centers. Similar to previous reports, the results from our first phase of the study showed that $35 \%$ of physicians were non-compliant with guidelines; however, following an intervention we were able to decrease non-compliance to $22 \%$. Our intervention also resulted in a significant increase in the number of patients who received a clear, well documented written recommendation.

Previous studies showed that age, bowel preparation quality, and number/types of polyps were associated with adherence to guidelines $[11,13]$. In our study, inadequate bowel preparation was associated with an accurate recommendation for early repeat colonoscopy (within 1 year). This is probably because an inadequate preparation warrants repeat colonoscopy regardless of other parameters, as stipulated in societal guidelines.

High-risk polyps (high-grade dysplasia, more than 3 polyps, polyps size $>1 \mathrm{~cm}$ ) were associated with non-adherent recommendations. This might be because of bad estimation of polyp size during colonoscopy, or because recommendations were issued prior to the pathological report.

Our revised electronic reporting platform allowed the physicians to fill in the recommended time for interval colonoscopy, based on the guidelines, the endoscopic report, and the final pathologic report. This user-friendly platform facilitated better compliance by our physicians, which resulted in more accurate recommendations.

\section{Summary Box}

\section{What is already known:}

- Colorectal cancer is a significant cause of mortality and morbidity

- Colonoscopy with polypectomy reduces the incidence of colorectal cancer and the associated mortality

- Recommendations for post-polypectomy surveillance intervals balance the risks and benefits of additional procedures

- Previous studies found that $10-50 \%$ of physicians are non-adherent to societal guidelines

\section{What the new findings are:}

- Absence of a structured reporting platform results in many cases without recorded recommendations

- Intervention significantly increases the number of recorded follow-up recommendations after polypectomy

- Intervention significantly increases the consistency of recommendations with societal guidelines
Our study had several limitations: we checked the electronic form for a short period, and only a few months after using it. Long-term follow up is required in order to better understand the long-term impact. Our platform is suitable for the specific reporting software we use in our hospitals; different electronic forms should be developed for different reporting platforms. Our platform was developed for hospital settings, but a different approach may be needed for community medicine.

In conclusion, we have shown that poor adherence to societal guidelines for post-polypectomy surveillance can be overcome by a simple intervention in the form of guideline reaffirmation and a structured reporting platform.

\section{References}

1. Jemal A, Bray F, Center MM, Ferlay J, Ward E, Forman D. Global cancer statistics. CA Cancer J Clin 2011;61:69-90.

2. Heitman SJ, Ronksley PE, Hilsden RJ, Manns BJ, Rostom A, Hemmelgarn BR. Prevalence of adenomas and colorectal cancer in average risk individuals: a systematic review and meta-analysis. Clin Gastroenterol Hepatol 2009;7:1272-1278.

3. Cunningham D, Atkin W, Lenz HJ, et al. Colorectal cancer. Lancet 2010;375:1030-1047.

4. Johnson CM, Wei C, Ensor JE, et al. Meta-analyses of colorectal cancer risk factors. Cancer Causes Control 2013;24:1207-1222.

5. Zauber AG, Winawer SJ, O'Brien MJ, et al. Colonoscopic polypectomy and long-term prevention of colorectal-cancer deaths. N Engl J Med 2012;366:687-696.

6. Kahi CJ, Imperiale TF, Juliar BE, Rex DK. Effect of screening colonoscopy on colorectal cancer incidence and mortality. Clin Gastroenterol Hepatol 2009;7:770-775.

7. Mandel JS, Church TR, Ederer F, Bond JH. Colorectal cancer mortality: effectiveness of biennial screening for fecal occult blood. J Natl Cancer Inst 1999;91:434-437.

8. Lieberman DA, Rex DK, Winawer SJ, Giardiello FM, Johnson DA, Levin TR. Guidelines for colonoscopy surveillance after screening and polypectomy: a consensus update by the US Multi-Society Task Force on Colorectal Cancer. Gastroenterology 2012;143:844-857.

9. Hassan C, Quintero E, Dumonceau JM, et al; European Society of Gastrointestinal Endoscopy. Post-polypectomy colonoscopy surveillance: European Society of Gastrointestinal Endoscopy (ESGE) Guideline. Endoscopy 2013;45:842-851.

10. Clark BT, Protiva P, Nagar A, et al. Quantification of adequate bowel preparation for screening or surveillance colonoscopy in men. Gastroenterology 2016;150:396-405.

11. Johnson MR, Grubber J, Grambow SC, et al. Physician nonadherence to colonoscopy interval guidelines in the veterans affairs healthcare system. Gastroenterology 2015;149:938-951.

12. Mysliwiec PA, Brown ML, Klabunde CN, Ransohoff DF. Are physicians doing too much colonoscopy? A national survey of colorectal surveillance after polypectomy. Ann Intern Med 2004;141:264-271.

13. Menees SB, Elliott E, Govani S, Anastassiades C, Schoenfeld P. Adherence to recommended intervals for surveillance colonoscopy in average-risk patients with 1 to 2 small $(<1 \mathrm{~cm})$ polyps on screening colonoscopy. Gastrointest Endosc 2014;79:551-557. 


\section{Supplementary materials}

Supplementary Table 1 Summary of ESGE, AGA and ASGE guidelines for post-polypectomy surveillance

\begin{tabular}{|c|c|c|}
\hline Association & $\begin{array}{c}\text { ESGE - European society of gastrointestinal } \\
\text { endoscopy [11] }\end{array}$ & $\begin{array}{l}\text { AGA - American gastroenterological Association [10] and } \\
\text { ASGE - American society of gastrointestinal endoscopy }\end{array}$ \\
\hline Conditions & \multicolumn{2}{|c|}{ Good bowel preparation, with complete removal of all polyps. } \\
\hline No polyps & 10 years & 10 years \\
\hline $\begin{array}{l}\text { Hyperplastic small polyps } \\
(<10 \mathrm{~mm}) \text { in recto-sigmoid }\end{array}$ & 10 years & 10 years \\
\hline $\begin{array}{l}1-2 \text { small }(<10 \mathrm{~mm}) \text { tubular } \\
\text { adenomas }\end{array}$ & 10 years & $5-10$ years \\
\hline 3-10 tubular adenomas & 3 years & 3 years \\
\hline 10 or more tubular adenomas & 3 years & 3 years or less \\
\hline $\begin{array}{l}1 \text { or more large }(>10 \mathrm{~mm}) \text { tubular } \\
\text { adenomas }\end{array}$ & 3 years & 3 years \\
\hline 1 or more villous adenoma & 3 years & 3 years \\
\hline High-grade dysplasia adenomas & 3 years & 3 years \\
\hline $\begin{array}{l}\text { Small sessile serrated }(<10 \mathrm{~mm}) \\
\text { with no dysplasia }\end{array}$ & 5 years & 5 years \\
\hline $\begin{array}{l}\text { Large sessile serrated adenoma } \\
(>10 \mathrm{~mm} \text { ) or dysplastic sessile } \\
\text { serrated or traditional serrated } \\
\text { adenoma }\end{array}$ & 3 years & 3 years \\
\hline Comments & $\begin{array}{l}\text { Patients who had high-risk adenoma in } \\
\text { previous colonoscopy remain at high risk, } \\
\text { and should have surveillance colonoscopy } \\
\text { after } 5 \text { years, even with no adenoma in the } \\
\text { colonoscopy }\end{array}$ & \\
\hline Bad preparation & In case of bad preparation (Boston $<6$ ), a repeat & colonoscopy within 1 year. \\
\hline
\end{tabular}


Supplementary Table 2 Relation between different variables and adherence to guidelines

\begin{tabular}{|c|c|c|c|c|c|c|c|c|c|c|}
\hline \multirow[t]{2}{*}{ Variable } & & \multicolumn{3}{|c|}{ Prior to intervention } & \multicolumn{3}{|c|}{ After intervention } & \multicolumn{3}{|c|}{ Total } \\
\hline & & Adherent & Not adherent & Total & Adherent & Not adherent & Total & Adherent & Not adherent & Total \\
\hline \multirow[t]{4}{*}{ Preparation } & Good preparation & 138 & 81 & 219 & 168 & 54 & 222 & 306 & 135 & 441 \\
\hline & Bad preparation & 31 & 7 & 38 & 31 & 1 & 32 & 62 & 8 & 70 \\
\hline & Total & 169 & 88 & 257 & 199 & 55 & 254 & 368 & 143 & 511 \\
\hline & P-value & & 0.03 & & & 0.007 & & & 0.0009 & \\
\hline \multirow[t]{4}{*}{ Endoscopic size } & $<1 \mathrm{~cm}$ & 127 & 59 & 186 & 154 & 28 & 182 & 281 & 87 & 368 \\
\hline & $>1 \mathrm{~cm}$ & 45 & 33 & 78 & 45 & 27 & 72 & 90 & 60 & 150 \\
\hline & Total & 172 & 92 & 264 & 199 & 55 & 254 & 371 & 147 & 518 \\
\hline & P-value & & 0.10 & & & 0.0001 & & & 0.0002 & \\
\hline \multirow{3}{*}{ Pathologic size } & $>1 \mathrm{~cm}$ & 34 & 32 & 66 & 44 & 20 & 64 & 78 & 52 & 130 \\
\hline & Total & 172 & 92 & 264 & 199 & 55 & 254 & 371 & 147 & 518 \\
\hline & P-value & & 0.01 & & & 0.03 & & & 0.001 & \\
\hline \multirow[t]{4}{*}{ Quantity of polyps } & 1-2 polyps & 123 & 58 & 181 & 134 & 37 & 171 & 257 & 95 & 352 \\
\hline & $3+$ polyps & 49 & 34 & 83 & 65 & 18 & 83 & 114 & 52 & 166 \\
\hline & Total & 172 & 92 & 264 & 200 & 55 & 254 & 372 & 147 & 518 \\
\hline & P-value & & 0.16 & & & 0.99 & & & 0.31 & \\
\hline \multirow[t]{3}{*}{ Dysplasia } & None & 94 & 63 & 157 & 89 & 24 & 113 & 183 & 87 & 270 \\
\hline & Low grade & 70 & 23 & 93 & 106 & 25 & 131 & 176 & 48 & 224 \\
\hline & High grade & 10 & 6 & 16 & 4 & 6 & 10 & 14 & 12 & 26 \\
\hline \multirow[t]{4}{*}{ Polyp type } & Non-villous & 123 & 46 & 169 & 153 & 38 & 191 & 276 & 84 & 360 \\
\hline & Villous & 51 & 46 & 97 & 46 & 17 & 63 & 97 & 63 & 160 \\
\hline & Total & 174 & 92 & 266 & 199 & 55 & 254 & 373 & 147 & 520 \\
\hline & P-value & & 0.01 & & & 0.24 & & & 0.0002 & \\
\hline \multirow{4}{*}{$\begin{array}{l}\text { High-risk vs. low- } \\
\text { risk polyps }\end{array}$} & Low risk & 82 & 25 & 107 & 88 & 11 & 99 & 170 & 36 & 206 \\
\hline & High risk & 92 & 67 & 159 & 111 & 44 & 155 & 203 & 111 & 314 \\
\hline & Total & 174 & 92 & 266 & 199 & 55 & 254 & 373 & 147 & 520 \\
\hline & P-value & & 0.02 & & & 0.01 & & & 0.01 & \\
\hline \multirow[t]{7}{*}{ Age } & Under 50 & 13 & 5 & 18 & 11 & 2 & 13 & 24 & 7 & 31 \\
\hline & $50-60$ & 34 & 18 & 52 & 47 & 6 & 53 & 81 & 24 & 105 \\
\hline & $60-70$ & 74 & 42 & 116 & 78 & 26 & 104 & 152 & 68 & 220 \\
\hline & $70-80$ & 43 & 23 & 66 & 52 & 19 & 71 & 95 & 42 & 137 \\
\hline & $80+$ & 10 & 4 & 14 & 11 & 2 & 13 & 21 & 6 & 27 \\
\hline & Total & 174 & 92 & 266 & 199 & 55 & 254 & 373 & 147 & 520 \\
\hline & P-value & & 0.95 & & & 0.21 & & & 0.45 & \\
\hline \multirow{4}{*}{$\begin{array}{l}\text { Physicians' } \\
\text { experience }\end{array}$} & $<5$ years & 47 & 24 & 71 & 66 & 16 & 82 & 113 & 40 & 153 \\
\hline & $>5$ years & 127 & 68 & 195 & 133 & 39 & 172 & 260 & 107 & 367 \\
\hline & Total & 174 & 92 & 266 & 199 & 55 & 254 & 373 & 147 & 520 \\
\hline & P-value & & 0.87 & & & 0.57 & & & 0.49 & \\
\hline
\end{tabular}

